\title{
POLUIÇÃO ATMOSFÉRICA E POSSÍVEIS EFEITOS À POPULAÇÃO DE RECIFE: AVALIAÇÃO DE MORTE CELULAR, RESPOSTAS INFLAMATÓRIAS E ESTRESSE OXIDATIVO EM CÉLULAS PULMONARES EXPOSTAS A MATERIAL PARTICULADO
}

\author{
Cleonilde Nascimento ${ }^{1 *}$, Sheilla Andrade ${ }^{2}$, Helotônio Carvalho ${ }^{1}$ \\ ${ }^{1}$ Departamento de Biofísica e Radiobiologia, UFPE; ${ }^{2}$ Instituto Aggeu Magalhães-Fiocruz Recife \\ *cl.manasci@gmail.com
}

\begin{abstract}
INTRODUÇÃO
Dados recentes da Organização Mundial de Saúde estimam que a poluição atmosférica seja responsável pela morte de aproximadamente três milhões de pessoas anualmente (1). A poluic ão atmosférica está diretamente relacionada ao aumento considerá vel nos casos de infecções respiratórias, sendo também associada ao desencadeamento ou agravamento de doenças graves como edema pulmonar, câncer de pulmão e doenças cardiovasculares (16). Há várias classes de poluentes atmosféricos e entre os principais encontra-se o material particulado. Seus riscos à saúde são determinados pelo tamanho, área superficial e composição das partículas, que são geradas normalmente pela queima de combustí veis fósseis em veículos automotores, indústrias e centrais termelé tricas e são formadas por um núcleo de carbono com diferentes materiais adsorvidos à sua superfície, como metais pesados, hidrocarbonetos, nitratos e sulfatos (7). 0 material particulado, é capaz de gerar espécies reativas de oxigênio (EROs) quando inalado $(9,10)$. Estas espécies altamente reativas podem causar danos ao DNA, proteínas e membranas celulares, que podem culminar na morte da célula, a qual pode se manifestar na forma de apoptose (9-12). Além disso, o material particulado também pode induzir respostas inflamatórias, com aumento na expressão de TNF- $\alpha$, IL-6, IL-8 e IL- $1 \beta$, sugerindo que o processo inflamatório gerado por material particulado possa estar relacionado aos efeitos nocivos destas partículas nos pulmões e no sistema respiratório como um todo (15-16). Recife possui uma população aproximada de 1,6 milhão de habitantes e uma frota de 700 mil veículos. Resultados prévios de estudos do nosso grupo de pesquisa indicam um aumento no número de internações hospitalares e mortes por doenças associadas à poluição atmosférica na cidade de Recife nos últimos 15 anos, que pode estar relacionado ao grande aumento da frota de veículos da cidade nesse mesmo período (8). Assim sendo, o propósito deste projeto é coletar e estudar a composição química orgânica e de metais, bem como o efeito do material particulado (MP) coletado da atmosfera de Recife, na indução de apoptose em células alveolares do tipo II humanas (A549) e avaliar a participaçã o de citocinas inflamatórias na resposta celular a esse material particulado.
\end{abstract}

\section{MATERIAIS E MÉTODOS}

Serão utilizados dois tipos de material particulado: um obtido de filtros expostos ao ambiente e outro derivado apenas de emissões de diesel, coletado de filtros instalados nos escapamentos de ô nibus. Parte do material particulado a ser utilizado será coletado na Universidade Federal de Pernambuco- UFPE, usando bombas de vácuo que forçam a passagem de ar através de filtros de policarbonato. Os estudos serão realizados através da análise de apoptose e medidas de produção de ROS por citometria de fluxo, e das concentrações de GSH e GSSG e dos níveis de enzimas antioxidantes através de PCR quantitativo em tempo Real. A induçã o de citocinas inflamatórias também será avaliada por PCR quantitativo em tempo Real.

\section{RESULTADOS E DISCUSSÃO}

Apesar de avanços ocorridos nas últimas décadas, que resultaram na redução dos níveis de emissões de veículos novos, o grande aumento da frota em cidades como São Paulo, Rio de Janeiro e Recife nos últimos anos é responsável por elevados níveis de poluiç ão, além de levar caos ao trânsito das grandes cidades brasileiras (8). Segundo dados do DETRAN-PE durante o período de 2002 a 2015 a frota de veículos de Recife praticamente duplicou, como pode ser observado na figura 1 .

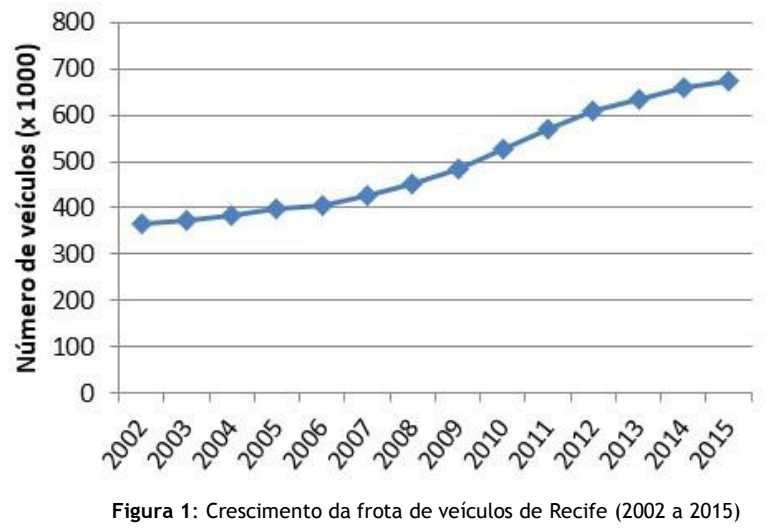

0 grande aumento da frota de veículos, que se repete na região metropolitana de Recife como um todo, é um fator que deve ter contribuído para o aumento nos níveis de poluição atmosférica em Recife e na região metropolitana. Recife, assim como outras metró poles brasileiras, infelizmente, ainda não possui um sistema de monitoramento de poluentes atmosféricos (8). Estudos recentes realizados por nosso grupo de pesquisa indicam um aumento no nú mero de internações hospitalares e mortes atribuídas a doenças relacionadas à poluição atmosférica em Recife e região metropolitana nos últimos anos. Tanto a bronquite aguda quanto 
bronquite crônica, enfisema e outras doenças respiratórias crônicas vêm apresentando um aumento ao longo dos 15 anos analisados, o que coincide com o aumento da frota de veículos de Recife nesse mesmo período. 0 mesmo se observa para o número de mortes relacionadas a doenças respiratórias. No caso de infarto do miocá rdio, tem havido um aumento no número de internações, sendo mais pronunciado na faixa etária acima de 60 anos. 0 número de mortes causadas por infarto do miocárdio não apresentou, no entanto, alterações importantes no período analisado. Os dados mais contundentes são as internações devidas a câncer de pulmão que apresentaram crescimento de mais de 10 vezes em relação aos últimos 10 anos. Apesar do aumento vertiginoso nas internações por câncer de pulmão, o número de mortes cresceu em menor grau, mas ainda mostra valores de até $90 \%$ de aumento em relação às mínimas do período analisado. Tais observações podem ser verificadas nas figuras abaixo $(2,3)$.

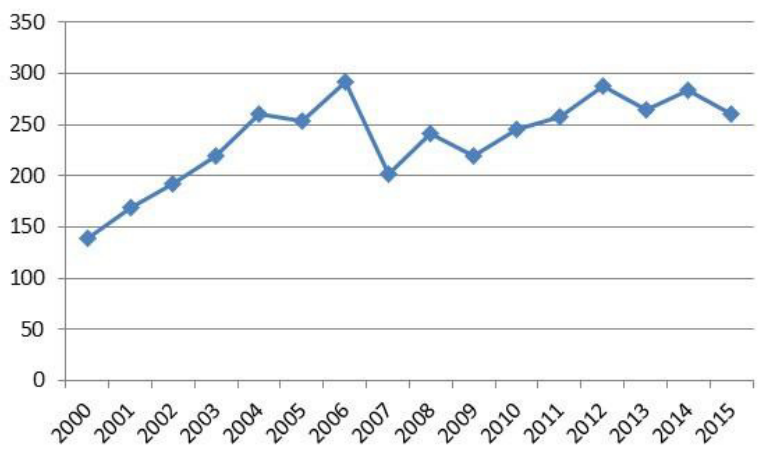

Figura 2: Número de internações na cidade de Recife devidas ao Infarto agudo do miocárdio nos últimos 15 anos.

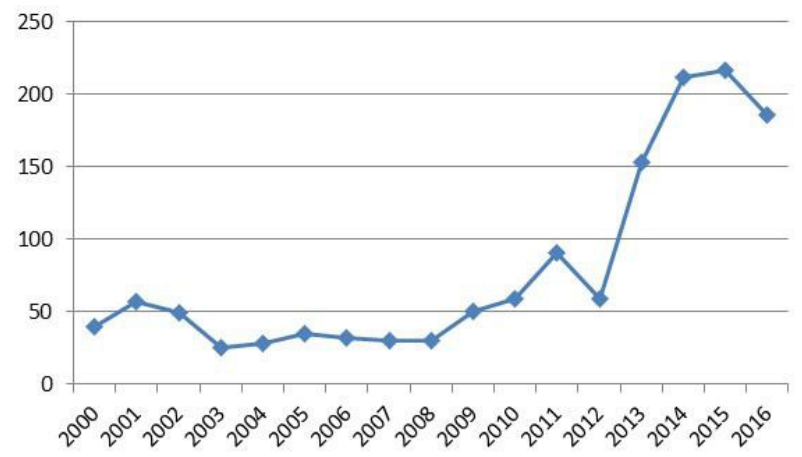

Figura 3: Número de internações na cidade de Recife devido ao câncer de pulmão nos ú ltimos 15 anos.

\section{PERSPECTIVAS}

Espera-se que os resultados obtidos possam nortear tratamentos futuros para distúrbios cardiorespiratórios causados por poluição atmosférica, além de servirem de subsídios para a adoção de polí ticas públicas que visem restringir ainda mais a emissão de poluentes por veículos automotores, e com isso reduzir os níveis de poluição atmosférica. Uma medida de política pública que teria grande efeito na diminuição dos níveis de poluição atmosférica seria o investimento maciço em transporte de massa (metrôs e trens). Infelizmente, o governo de Pernambuco e a prefeitura de Recife não têm feito investimentos importantes nessa área. Esperase também que os resultados deste projeto, possam ajudar as autoridades a realmente assumir os transportes de massa como prioridade, visto que apenas a melhoria e o aumento da capacidade do transporte público devem incentivar as pessoas a deixarem seus carros em casa, contribuindo tanto para uma reduçã o dos níveis de poluição como para uma melhoria no caótico trâ nsito da cidade.

\section{REFERÊNCIAS}

COHEN, A.J.; BRAUER, M.; BURNETT, R. et al. (2017) Estimates and 25-year trends of the global burden of disease attributable to ambient air pollution: an analysis of data from the Global Burden of Diseases Study 2015. Lancet, 389:1907-1918.

ANDERSON, J.O.; THUNDIYIL, J.G.; STOLBACH, A. (2012) Clearing the air: a review of the effects of particulate matter air pollution on human health. J Med Toxicol. 8:166-75.

GUARNIERI, M.; BALMES, J.R.; (2014) Outdoor air pollution and asthma. Lancet. 383:1581-1592.

SHAH, A.S; LANGRISH, J.P.; NAIR, H.; MCALLISTER, D.A.; HUNTER, A.L.; DONALDSON, K.; NEWBY, D.E.; MILLS, N.L. (2013) Global association of air pollution and heart failure: a systematic review and meta-analysis. Lancet. 382:1039-1048.

FAJERSZTA, J.N.L.; VERAS, M.; BARROZO, L.V.; SALDIVA, P. (2013) Air pollution: a potentially modifiable risk factor for lung cancer. Nat Rev Cancer. 13:674-8.

YANG, Y.; LI, R.; LI, W.; WANG, M.; CAO, Y.; WU, Z.; XU, Q. (2013) The association between ambient air pollution and daily mortality in Beijing after the 2008 olympics: a time series study. PLoS One. 8(10):e76759.

KATSOUYANNI, K. (2003) Ambient air pollution and health. Brit Med Bull. 68: 143-156.

CARVALHO, H. (2016) The air we breathe: differentials in global air quality monitoring. Lancet Respir Med. 4(8):603-605.

GONZALEZ-FLECHA B. (2004) Oxidant mechanisms in response to ambient air particles. Mol Aspects Med. 25:169-82.

GHIO, A.J.; CARRAWAY, M.S.; MADDEN, M.C. (2012) Composition of air pollution particles and oxidative stress in cells, tissues, and living systems. J Toxicol Environ Health B Crit Rev. 15:1-21.

HALLIWELL, B. AND GUTTERIDGE, J.M.C. (2007) Free Radicals in Biology and Medicine. Oxford University Press, 4th ed., 2007.

MATÉS, J.M.; SEGURA, J.A.; ALONSO, F.J.; MÁRQUEZ, J. (2012) Oxidative stress in apoptosis and cancer: an update. Arch Toxicol. 86:1649-65.

MEIER, P.; VOUSDEN, K.H. (2007) Lucifer's labyrinth - ten years of path finding in cell death. Mol Cell. 28:746-54.

DANIAL, N.N.; KORSMEYER, S.J. (2004) Cell death: critical control points. Cell. 116:205-19.

ORONA, N.S.; ASTORT, F.; MAGLIONE, G.A.; SALDIVA, P.H.N.; YAKISICH, J.S.; TASAT, D.R. (2014) Direct and indirect air particle cytotoxicity in human alveolar epithelial cells. Toxicology in Vitro. 28: 796-802.

KIM, J.A.; CHO, J.H.; PARK, I.H.; SHIN, J.M.; LEE, S.A.; LEE, H.M. (2016) Diesel Exhaust Particles Upregulate Interleukins IL-6 and IL8 in Nasal Fibroblasts. PLOS ONE 11(6): e0157058.doi:10.1371/journal.pone.0157058.

CASTRO, L.P; MENCK, C.F.M.; CARVALHO, H. (2017) Diesel exhaust particles induce cell death in A549 cells accompanied by p53independent increased expression of pro-apoptotic proteins. (manuscrito em finalização)

MASON, R.J.; WILLIAMS, M.C. ALVEOLAR TYPE II CELLS. IN: CRYSTAL RG, WEST, J.B., et al., ed. The Lung: Scientific Foundations. 2nd ed. Philadelphia: Lippincott-Raven, Ltd., 1997. Mason, R.J. (2006) Biology of alveolar type II cells, Respirology, 11:S12-S15.

CARVALHO, H.; EVELSON, P.; SIGAUD, S.; GONZALEZ-FLECHA, B. (2004) Mitogen-activated protein kinases modulate $\mathrm{H} 2 \mathrm{O} 2$-induced apoptosis in primary rat alveolar epithelial cells. J Cell Biochem., 92:502-13. 
CARVALHO, H (2016) The end of diesel-powered cars? Lancet Respir Med. 4(1):e2-3.

CARVALHO, H.; ORTOLAN, T.; PAULA, T.; LEITE, R.A.; WEINLICH, R.; AMARANTE-MENDES, G.P.; MENCK, C.F.M. (2008) Sustained activation of $\mathrm{p} 53$ in confluent nucleotide excision repair-deficient cells resistant to ultraviolet-induced apoptosis. DNA Repair, 7:922931.

RAHMAN, I.; KODE, A.; BISWAS, S.K. (2006) Assay for quantitative determination of glutathione and glutathione disulfide levels using enzymatic recycling method. Nat Protoc.1:3159-3165.

MILLER, E.W.; ALBERS, A.E.; PRALLE, A.; ISACOFF, E.Y.; CHANG, C.J. (2005) Boronate-based fluorescent probes for imaging cellular hydrogen peroxide. J Am Chem Soc 127, 16652-16659.

MAHIPAL, S.V.; SUBHASHINI, J.; REDDY, M.C.; REDDY, M.M.; ANILKUMAR, K.; ROY, K.R.; REDDY, G.V.; REDDANNA, P. (2007) Effect of 15-lipoxygenase metabolites, 15-(S)-HPETE and 15-(S)HETE on chronic myelogenous leukemia cell line K-562: reactive oxygen species (ROS) mediate caspase-dependent apoptosis. Biochem Pharmacol. 74:202-214. 